\title{
The Review on Adsorption and Removing Ammonia Nitrogen with Biochar on its Mechanism
}

\author{
LIANG Peiyu ${ }^{\mathrm{a}}$,YU Haiou ${ }^{\mathrm{b}}$, HUANG Jinling ${ }^{\mathrm{c}}$, ZHANG Yuting ${ }^{\mathrm{d}}$ and CAO Hongyang ${ }^{1, \mathrm{e}}$ \\ College of Urban and Environmental Science Tianjin Normal University, Tianjin 300387, China \\ arambleinthecloud@126.com, ${ }^{\mathrm{b}} 13920335630 @ 163 . c o m,{ }^{\mathrm{c}}$ Summerhuang78@163.com, \\ dZyt114@foxmail.com, ${ }^{\mathrm{e} 2393456283 @ q q . c o m}$
}

\begin{abstract}
The study on decreasing ammonia-nitrogen has received great attention in recent years. This paper summarizes the adsorption mechanism and the influencing factors. Thus, the feasibility of adsorption using biochar has been indicated. A few issues were proposed for the further study: the industrial application research on treatment, modification method for improving the efficiency of adsorption, desorption and regeneration of biochar,model of adsorption mechanism, the physical and chemical properties of soil .
\end{abstract}

\section{Introduction}

Water eutrophication pollution because of ammonia-nitrogen has become a serious environmental problem, which has led to a widespread concern of researchers. Currently, the main methods to remove ammonia-nitrogen include: biological nitrification-denitrification, break point chlorination, air stripping, chemical precipitation, ion exchange and adsorption method, et $\mathrm{al}^{[1,2]}$. Among them, the adsorption method is considered to be a very promising technique to remove the ammonia-nitrogen waste water because of its simple and effective process, lower operating cost and economical and practical property ${ }^{[3]}$. Adsorbents selection is the key for adsorption and the main materials used to adsorb ammonia-nitrogen at present are: fly ash, zeolite, sepiolite, limestone, charcoal, bamboo charcoal, and activated carbon, et $\mathrm{al}^{[4,10]}$. However, all of these materials require a secondary treatment, which makes the process cost increase and therefore cannot be popularized to use. In recent years, as a new adsorbent, biochars have been widely used in the field of waste water treatment due to its large specific surface area, strong pore structure, simple process and it does not require activation or secondary treatment.

Currently, there have been numerous reports about organic matter or heavy metals adsorption by biochars, however, the research on ammonia-nitrogen is less. China has abundant biochar sources, and biochars can serve as a good soil conditioner when they are

\footnotetext{
1 Author and *Corresponding author: LIANG Peiyu (1978-),Female, Doctor. Mainly engaged in soil pollution remediation research. E-mail: rambleinthecloud@126.com
} 
returned to the fields after ammonia-nitrogen adsorption reaching saturation, which has increased and improved the soil fertility. The study of the ammonia-nitrogen adsorption mechanism by biochar and its potential influencing factors in terms of dynamics and thermodynamics conducted a preliminary exploration of biochar application in ammonia-nitrogen processing field ${ }^{[11,13]}$.

\section{The research progress in adsorption of nitrate nitrogen using biochar}

The source of biochar with the adsorption effect to ammonia nitrogen is rich $^{[16-33]}$. Furthermore, the different adsorption properties are demonstrated, as the biochars are made of different biomass materials ${ }^{[14,15]}$. Most adsorption kinetics of biochars to ammonia nitrogen is in accord with the pseudo-first-order or pseudo-second-order kinetic model. Based on the analysis of adsorption isotherm model of different adsorption materials, the ammonia nitrogen adsorption of these biochars is roughly consistent with Langmuir and Freundlich adsorption isotherm model.

\section{Mechanism and Influence Factors of Ammonia Nitrogen Adsorption on Biological Carbon}

\subsection{Analysis on adsorption mechanism}

Many scholars have believed that different kinds of biochar have different effects on the adsorption to ammonia nitrogen, and the adsorption mechanisms are different under the different reaction conditions.

\subsubsection{Freundlich adsorption}

Ma and other scholars have found that the Freundlich equation $\left(\mathrm{R}^{2}=0.9762\right)$ is suitable for describing the behavior of the ammonia nitrogen adsorption of biochar, and the main form is the heterogeneous adsorption of the multi molecular layer ${ }^{[16,24,31,32,33]}$.

\subsubsection{Mineralization or assimilation}

Yang et al. have discovered that the decrease of ammonia nitrogen can be slowed down by promoting the mineralization of organic nitrogen or reducing the assimilation of inorganic nitrogen by microorganisms ${ }^{[21]}$.

\subsubsection{Quasi-second order kinetic model}

Zheng et al. have found that the adsorption of biochar to the ammonia nitrogen in water can be well fitted by the quasi-second-order equation with the highest correlation coefficient of 0.996 . Moreover, the equilibrium adsorption capacity calculated from the quasi-second order adsorption kinetics equation is closer to test values. It indicates that the quasi -second-order model can simulate the adsorption process better.

The correlation coefficient of Freundlich isothermal equation is 0.996 , while that of Langmuir isothermal equation is 0.957 , so the adsorption of ammonia nitrogen in water by biochar is more consistent with the Freundlich isothermal adsorption model ${ }^{[16,24,28,34]}$. 


\subsubsection{Physical adsorption}

It is generally accepted that $\Delta \mathrm{G}^{\theta}$ is in the range of $-20-0 \mathrm{KJ} \cdot \mathrm{mol}^{-1}$ for physical adsorption. While $-800-40 \mathrm{KJ} \cdot \mathrm{mol}^{-1}$ for chemical adsorption. In the Ma's study, it is found that $\Delta \mathrm{G}^{\theta}$ is $-14.66 \mathrm{KJ} \cdot \mathrm{mol}^{-1} 、-15.24 \mathrm{KJ} \cdot \mathrm{mol}^{-1}$ and $-13.46 \mathrm{KJ} \cdot \mathrm{mol}^{-1}$ respectively, indicated the adsorption of DMBC400 on ammonia nitrogen was mainly based on physical adsorption ${ }^{[16]}$. Gao et al. Have revealed that the coexisting ion $\mathrm{Na}^{+}$has not significant effect on the adsorption of biachar to ammonia nitrogen, and the ion exchange is not obvious. This adsorption is multi molecular layer adsorption which based on physical adsorption ${ }^{[24]}$.

\subsubsection{Chemical adsorption}

The theoretical equilibrium adsorption capacity calculated from the quasi-second-order dynamic equation is $1.8836 \mathrm{mg} / \mathrm{g}$, which is very close to the actual adsorption capacity $(1.8987 \mathrm{mg} / \mathrm{g})$ during the equilibrium time. So the adsorption kinetics of CSBC400 to ammonia nitrogen is accorded with the quasi-second-order equation, which indicated that the adsorption of CSBC400 is a chemical adsorption. Based on the $\mathrm{R}^{2}$ of the Langmuir model, the fitting data have perfectly showed that the adsorption to ammonia nitrogen often occurs in monolayer. On the other hand, the $\mathrm{R}^{2}$ of the Langmuir model is usually more than 0.95 , which indicated that there is a certain degree of physical adsorption, but the chemical adsorption is more favorable because $\mathrm{n}^{-1}>1^{[27,31,33,35]}$.

\subsubsection{Langmuir-Freundlich adsorption}

The squares of the isothermal adsorption correlation coefficients of CSBC400 to ammonia nitrogen are listed from high to low: Langmuir-Freundlich $\left(R^{2}=0.9844\right)>$ Langmuir $\left(\mathrm{R}^{2}=0.9797\right)>$ Freundlich $\left(\mathrm{R}^{2}=0.9772\right)>$ Temkin $\left(\mathrm{R}^{2}=0.9699\right)$. We can observe from it that for the adsorption data of $\mathrm{CSBC} 400$ to ammonia nitrogen, Freundlich adsorption isothermal equation is the best fitted one ${ }^{[27,28,33,36,38]}$.

\subsubsection{Langmuir type}

Xing et al. have found that the Langmuir equation can describe the adsorption behavior of biochar to ammonia nitrogen more accurately. This adsorption of biochar is in accordance with the Langmuir adsorption isotherm, indicated this is a homogeneous monolayer adsorption ${ }^{[29,30]}$.

\subsubsection{Pseudo two order kinetics}

From the regression correlation coefficients of Adsorption kinetic fitting curve for adsorbing ammonia nitrogen, it is observed that the correlation coefficients of the pseudo-two-order equations are 0.9979 and 0.9940 respectively, when the ammonia nitrogen concentrations are $10 \mathrm{mg} / \mathrm{L}$ and $5 \mathrm{mg} / \mathrm{L}$. It is shown that the pseudo-two-order equation can better describe the adsorption kinetics of ammonia nitrogen on the biochar. The regression correlation coefficients are all higher than 0.99 , and the qecal obtained from the pseudo-two-order equation is very close to the experimental results obtained from the qeexp. The pseudo-two-order model includes all the adsorption processes, such as external liquid film diffusion, surface adsorption and internal diffusion of particles, so that the process of adsorption is explained by it more comprehensively ${ }^{[29]}$. 


\subsection{Influencing factors}

\subsubsection{The dosage of biochar}

Under the condition that the concentration of ammonia nitrogen and other conditions remain unchanged, the adsorption rate increase significantly when the dosage of biochar is added. This is due to the increase of active site for adsorption, which cause the increase of absorbate ultimately ${ }^{[16]}$.

The adsorption effect to ammonia nitrogen is positively correlated with the dasage of biochar, but not directly proportional to it. The reason can be explained as the following: when ammonia nitrogen concentration was ascertain, the more biochars are added, the more adsorption sites are provided, and the more easily the ammonia nitrogen is absorbed by these active sites. However, with the increase of the concentration of biochar, the competitive adsorption occurs on the surface active sites so that the adsorption capacity to ammonia nitrogen on the unit area is gradually reduced ${ }^{[22,31,39,40]}$.

\subsection{2 $\mathrm{pH}$ value}

The main reason why the $\mathrm{pH}$ value affects adsorption process of ammonia nitrogen is that $\mathrm{pH}$ has changed the form of ammonia nitrogen in water. In the range of $\mathrm{pH} 2$ to 4 , the adsorption rate increased with the increase of $\mathrm{pH}$ value. In the range of $\mathrm{pH} 5$ to 8 , the adsorption rate gradually stabilized with the increase of $\mathrm{pH}$. When $\mathrm{pH}>10$, the adsorption

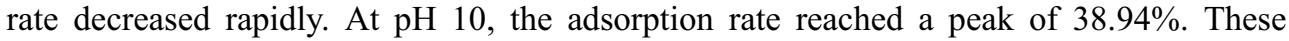
changes mainly result from the content of $\mathrm{H}^{+}$and ammonia nitrogen form in solution. At lower $\mathrm{pH}$ values, the solution enriched with $\mathrm{H}^{+}$will impede the adsorption to ammonia nitrogen because of the competitive effect between $\mathrm{H}^{+}$and $\mathrm{NH}^{4+}$, which have the same adsorption sites. Increasing $\mathrm{pH}$ value will lead to the increase of the adsorption to $\mathrm{NH}^{4+}$ by reducing the competition of $\mathrm{H}^{+}$and $\mathrm{NH}^{4+}$ on the adsorption site. On the other hand, the ammonia nitrogen in solution is in two forms: $\mathrm{NH}^{4+}$ and $\mathrm{NH}_{3} \cdot \mathrm{H}_{2} \mathrm{O}$. Under the neutral or acidic conditions, $\mathrm{NH}^{4+}$ is the main form of existence. Hen the $\mathrm{pH}$ value is high, $\mathrm{NH}^{4+}$ changes into $\mathrm{NH}_{3} \cdot \mathrm{H}_{2} \mathrm{O}$, which is not conducive to the adsorption to ammonia nitrogen. The change of the $\mathrm{pH}$ value may also have an effect on the surface charge of biochar, and the protonation and deprotonation of surface functional groups will lead to the formation of a double electric layer on the surface of biochar. If $\mathrm{pH}<\mathrm{pHpzc}(\mathrm{pH}$ at the point of zero charge), the surface charge of biochar is positive, and the adsorption to $\mathrm{NH}^{4+}$ will depend on the exchange of positive ions on the biochar surface and $\mathrm{NH}^{4+}$ in the solution. If $\mathrm{pH}>\mathrm{pHpzc}$, the surface charge is positive and the adsorption depends on electrostatic effect ${ }^{[16]}$. In brief, lower or higher $\mathrm{pH}$ values are not suitable for adsorption to $\mathrm{NH}^{4+[24]}$, and the $\mathrm{pH}$ values within the neutral alkaline range are optimal ${ }^{[27,41]}$.

Additionally, at lower $\mathrm{pH}$ values, the decrease of adsorption capacity also results from high protonated effect of the functional groups ( such as $\mathrm{C}=\mathrm{O}, \mathrm{COO}-$ ) to the biochar surface, on which some positive ions can repulse the polar attraction of $\mathrm{NH}^{4+}$. The similar conclusion has been supported by some previous studies about using zeolite or activated carbon to adsorb amino salt ${ }^{[42-45]}$.

At presence of bacteria, the removal rate of biochar-immobilized microbial agent to ammonia nitrogen first raises then declines. At $\mathrm{pH} 7.5$, the removal rate reaches about $85 \%$. Then it decreases rapidly if $\mathrm{pH}$ is more than 7.5 . when $\mathrm{pH}=10$, it is down to $48 \%$. There are two steps in the removal reaction of nitrifying bacteria agent: ammonia oxidation and nitrite oxidation. Ammonia oxidation depends on the combination of AMO (ammonia monooxygenase) and HAO (hydroxylamine oxidoreductase). As the matrix of ammonia 
oxidizing bacteria, free ammonia in water sample will increase at higher $\mathrm{pH}$. In a certain concentration range, the increase of free ammonia concentration promotes the activity of AMO. However, when the free ammonia increases to a certain concentration with the increase of $\mathrm{pH}$ value, it will inhibit the nitrification bacteria, which makes both the microbial activity and the removal ability of ammonia nitrogen decrease ${ }^{[23,46-48]}$.

\subsubsection{Particle size of biochar}

The particle size of biochar has a great influence on the adsorption capacity. The smaller the particle size is, the more ammonia nitrogen will be adsorbed. The surface area of the biochar is the key factor affecting the adsorption capacity. For unit mass of biochar, the smaller the particle size is, the larger the surface area is, and the more obvious the surface energy is. So the adsorption effect increases correspondingly ${ }^{[16,27]}$. Additionally, this trend is also related to the surface area of the adsorbent and the diffusion rate of the absorbed material. In general, assuming that the adsorption rate depends only on the surface area, the surface area of smaller particle will increase, and then dispersion path is shorten in the small adsorbent particle, because it provide a better opportunity to make the absorbed ions penetrate all internal pore structure ${ }^{[33,49,50]}$. The effect of particle size on the adsorption capacity of ammonia nitrogen has been also confirmed by the use of zeolite previously $[51,52]$.

\subsubsection{Ammonia nitrogen in the inlet}

When the influent ammonia nitrogen concentration and water temperature are higher, the nitrification bacteria and heterotrophic bacteria in the biochar filter are competitive, and higher ammonia nitrogen concentration has an effect on $\mathrm{COD}_{\mathrm{Mn}}$ removal. So the raw water with more ammonia nitrogen should be taken to the biological pretreatment ${ }^{[26]}$.

\subsubsection{Effect of modified activated method on the adsorption of biochar}

$\mathrm{H}_{2} \mathrm{SO}_{4}-\mathrm{CC}, \mathrm{NaOH}-\mathrm{CC}, \mathrm{H}_{3} \mathrm{PO}_{4}-\mathrm{CC}, \mathrm{KOH}-\mathrm{CC}, \mathrm{ZnCl}_{2}-\mathrm{CC}$ and $\mathrm{N}-\mathrm{CC}$ had been used to adsorb $100 \mathrm{mg} \cdot \mathrm{L}^{-1}$ ammonia nitrogen for $12 \mathrm{~h}$, and a steady state was reached. The results showed that comparing to N-CC, NaOH-CC, $\mathrm{H}_{3} \mathrm{PO}_{4}-\mathrm{CC}, \mathrm{KOH}-\mathrm{CC}, \mathrm{ZnCl}_{2}-\mathrm{CC}$ and $\mathrm{H}_{2} \mathrm{SO}_{4}-\mathrm{CC}$ had a more obvious effect on adsorption to ammonia nitrogen ${ }^{[28]}$. After modified by sodium hydroxide, biochar is suitable for adsorbing ammonia nitrogen, which results from the increase of specific surface area and acidic functional groups such as hydrocarbon bond, hydroxyl and ethylenic bond ${ }^{[24]}$. The stronger oxidizing the acid is, the more oxygenous acid groups are produced on the surface of the biochar, which increase the hydrophilicity and the cation exchange capacity of the carbon. These are conducive to improve the adsorption capacity to ammonia nitrogen ${ }^{[17,18]}$. After modification, the biochar surface cavity was significantly increased, but the ash content was dramatically reduced. Especially after modification by nitric acid, carboxyl and phenolic hydroxyl group can be formed on the surface ${ }^{[53-55]}$.

\subsubsection{Reaction time}

In the adsorption test, the changing trends of ammonia nitrogen concentration following the change of time were similar, that is, with the increase of time, the concentration of ammonia nitrogen first gradually decreases, which decrease fastly, and then gradually tends to be stable. After $60 \mathrm{~min}$, the equilibrium is reached. The faster decrease of ammonia 
nitrogen concentration is resulted from the adsorption captivity of biochar, which will achieve the maximum with the adsorption lasting. Thereafter, the ammonia nitrogen concentration falls slowly and fluctuates in the vicinity of the equilibrium point in the end. It is indicated that the adsorption of biochar to ammonia nitrogen can be carried out reversely under the certain conditions ${ }^{[22,29,33]}$. This process can be divided into three stages: the first one is the initial rapid uptake stage, a physical process, in which ions transport to solid and liquid depending on the concentration. Physical adsorption and ion balance between solid and liquid are disclosed in the second stage, and a small amount of binding $\mathrm{NH}^{4+}$ is desorbed. finally, due to the diffusion within the particles, chemical adsorption processes occur very slowly until saturation ${ }^{[56,57]}$. Some similar trends have also been reported in other studies ${ }^{[58]}$.

\subsubsection{Appearance properties and structures of biochar}

There are some reasons for the different adsorption capacity of biochar, such as specific surface area, hydrophobicity, surface functional groups, pore structure, composition, et al. On the other hand, the chemical composition of different raw materials also can affect the composition and content of biochar, and the element content of the biochar showed a linear correlation with that of the raw materials ${ }^{[21]}$. Rice husk biochar has a certain removal effect on ammonia nitrogen, and the maximum removal rate reaches $30 \%$. Because in the conditions of no oxygen and low temperature $700^{\circ} \mathrm{C}$, the rice husk can be converted into a porous carbon material with high organic carbon content and high adsorption capacity, which is low solubility, and has highly carboxylic acid esters and aromatic structure, relatively large porosity and specific surface area endow it with a certain adsorption capacity. From the analysis, it is discovered that after immobilized by rice husk biochar, the nitrifying bacteria agent maintains a higher removal rate to ammonia nitrogen. The removal rate can reach $85 \%$, is higher than using rice husk biochar alone ${ }^{[23,59-63]}$.

\subsubsection{Initial ammonia nitrogen concentration}

The ammonia nitrogen removal rate of nitrifying bacteria agent immobilized by rice husk biochar will increase with the decrease of ammonia nitrogen concentration in water sample. When ammonia nitrogen concentration is less than $300 \mathrm{mg} / \mathrm{L}$, ammonia nitrogen removal rate can be maintained at more than $80 \%$. When the concentration of ammonia nitrogen is more than $300 \mathrm{mg} / \mathrm{L}$, the removal rate gradually decreases from $80 \%$ to $25 \%$. That is to say, the nitrifying bacteria agent immobilized by rice husk biochar preparation is more suitable for treating the water sample in which the ammonia nitrogen concentration is less than $300 \mathrm{mg} / \mathrm{L}^{[22]}$. Some studies have shown that the adsorption capacity is obviously improved with the increase of ammonia nitrogen concentration, which may result in low ion concentration, at low concentrations. There are too many vacant active sites in the biochar, so the adsorption capacity depends on the initial concentration. However, with the increase of ion concentration, more and more $\mathrm{NH}^{4+}$ appears on the active site because of the increase of adsorption capacity ${ }^{[64-66]}$.

\subsubsection{Pyrolysis temperature}

The effect of temperature on the activity of the biochar is greater. The activity decreases with the decrease of temperature, and the adsorption capacity increases with the increase of temperature ${ }^{[29]}$. It was considered that when the temperature is high, the diffusion of ammonia nitrogen to the biological carbon microporous will be enhanced because of the 
reaction of $\mathrm{NH}^{4+}$ and the functional groups. But at high temperature, the adsorption rate is relatively small ${ }^{[26]}$. Although the specific surface area of the biochar can increase with the increase of temperature, excessively high temperature will lead to the reduction of the specific surface area caused by the formation of medium or large holes during from the microporouses ${ }^{[23,25]}$. The increase of pyrolysis temperature will lead to the decrease of -OH group in the biochar ${ }^{[30,67]}$.

\subsubsection{Immobilized bacteria agent and microorganisms}

After immobilized by rice husk biochar, the nitrifying bacteria agent maintains a higher removal rate to ammonia nitrogen. The removal rate can reach $85 \%$, is higher than using rice husk biochar alone. Yang et al. ${ }^{[21]}$ have discovered that the reduction of ammonia nitrogen caused by the affected microbial function is about $42 \%$ of the total reduction ${ }^{[23]}$.

\subsubsection{Coexisting cation}

With the increase of $\mathrm{Na}^{+}$and $\mathrm{Ca}^{2+}$, the adsorption capacity of DMBC400 to ammonia nitrogen is gradually decreased. When $\mathrm{Ca}^{2+}$ and $\mathrm{Na}^{+}$exist simultaneously, the inhibition of DMBC400 to ammonia nitrogen is mainly due to the competition of these cations and $\mathrm{NH}^{4+}$. Furthermore, with the increase of the initial concentration of the cation concentration, the competition will be intensified. Under the same cation concentration, DMBC400 is more affected by $\mathrm{Na}^{+}$than by $\mathrm{Ca}^{2+}$. The main reason is that comparing to the $\mathrm{Ca}^{2+}$ hydrated ionic radius, the $\mathrm{Na}^{+}$hydrated ionic radius is smaller and similar to the radius of the monovalent $\mathrm{NH}^{4+}$ ion hydration, which leads to a stronger competitive adsorption between the $\mathrm{Na}^{+}$and the $\mathrm{NH}^{4+}$ in solution ${ }^{[16,24,30]}$.

\section{Conclusion}

(1)Different sources of biochars can have a good effect on ammonia nitrogen adsorption.

(2)The mechanism of ammonia-nitrogen adsorptive removal by biochars includes physical adsorption, chemical adsorption, et al.

(3)Biochars adsorption of ammonia nitrogen is influenced by many factors including the biochar pyrolysis temperature, $\mathrm{pH}$ value, adsorption time, interfering ions, adsorption reaction temperature, initial ammonia concentration, et al.

\section{Prospects}

Biochars have a great advantage in the field of water procession and agricultural soil fertility maintenance and remediation. However, currently the study of the biochars ammonia-nitrogen adsorption mechanism, potential influential factors and the impact of different sources is still on the initial stage. Therefore, we should continue to carry out the following research in the future:

(1) Evaluation index of the adsorption efficiency of ammonia nitrogen when the biochars are used to remove multiple-componented pollutants.

(2) Establishing the model of relevant adsorption mechanism.

(3) Practical research on the industrial water treatment.

(4)The modification methods to improve the adsorption efficiency. Subsequent trials should explore other modifiers which impact the effects of biochars ammonia-nitrogen adsorption in order to find the best modifier. 
(5) Desorption and regeneration of biochars.

(6)Previous studies suggest that the adsorption of ammonia-nitrogen is static. However, actually ammonia-nitrogen is dynamic. Therefore, it is necessary to investigate thoroughly the dynamic adsorption of biochars and the removal situation of composite water bodies

(7) The comprehensive impact of adsorption on soil physical and chemical properties and the mechanisms, et al.

\section{Acknowledgements}

Project supported by the Science and technology development fund of Higher Education foundation from the Education Commission of Tianjin, China (Grant mumber20130518.).

\section{References}

1. Mahajan O.P., Youssef A., Walk P.L. Jr, Surface treated activated carbon for removal of ammonia from water, J. Separation Science and Technology. 13(6) (1978) 487-499.

2. Metcalf, Eddy, Tchobanoglous G, Wastewater Engineering Treatment, J. Disposal, Reuse. New York: McGraw-Hill International Editions, USA, 1991.

3. Aziz H.A., Adlan M.N., Zahari M.S.M., Removal of ammonical nitrogen $\left(\mathrm{N}_{-} \mathrm{NH}_{3}\right)$ from municipal solid waste leachate by using activated carbon and limestone, J. Waste Management and Research. 22(5) (2004) 371-375.

4. Abdulrazzaq H, Hamdan $\mathrm{J}$, Ahmed $\mathrm{H}$, Characterization and stabilisation of biochars obtained from empty fruit bunch, wood, and rice husk, J. Bioresources. 9(2) (2014) 98-2888.

5. Balci S., Dincel Y., Ammonium ion adsorption with sepiolite:Use of transient uptake method, J. Chemical Engineering and Processing. 41(1) (2002) 79-85.

6. Celik M.S., Ozdermir B., Turan M., Removal of ammonia by natural clay minerals using fixed and fluidized bed column reactors, J. Water Supply. 1(1) (2001) 81-98.

7. Demir A., Günay A., Debik E., Ammonium removal from aqueous solution by ion-exchange using packed bed natural zeolite, J. Water S A. 8(3) (2002) 329-335.

8. Hollister C.C., Bisogni J.J., Lehmann J., Ammonium nitrate and phosphate sorption to and solute leaching from biochars prepared from corn stover (Zea mays L.)and oak wood ( Quercus ssp), J. Journal of Environmental Quality. 42(1) (2013) 137-144.

9. Tang Dengyong, Zheng Zheng, Guo Zhaobing, Study on ammonia-nitrogen adsorption from low concentration waste water by modified zeolite and its desorption, J. Chinese Journal of Environmental Engineering. 5(2) (2011) 293-296.

10. Tian Manli, Zeng Zhiyong, Jiang Zhengwu, Progress of Preparation and Applications of Bamboo Charcoal, J. Materials Review. 29(01) (2015) 143-146.

11. Beesley L., Moreno-Jiménez E., Gomez-Eyles J.L., A review of biochars' potential role in the remediation revegetation and restoration of contaminated soils, J. Environmental Pollution. 159(12) (2011) 3269-3282.

12. Ahmad M., Rajapaksha A.U., Lim J.E., Biochar as a sorbent for contaminant management in soil and water: A review, J. Chemosphere. 99 (2014) 13-33.

13. Ogbonnaya U., Semple K. Impact of biochar on organic contaminants in soil: a tool for mitigating risk, J. Agronomy. 3(2) (2013) 349-375.

14. Roberts K G, Gloy B A, Joseph S, Life cycle assessment of biochar systems: Estimating the energetic, economic, and climate change potential, J. Environmental Science\&Technology. 44(2) (2009) 827-833.

15. Lehmann J. A handful of carbon, J. Nature. 447(7141) (2007) 143-144.

16. Ma Fengfeng, Zhao Baowei, Diao Jingru, Ammonium Adsorption Characteristics in 
Aqueous Solution by Dairy Manure Biochar, J. Environmental Science. 36(5) (2015) 1678-1685

17. Yi Chao, Lu Shaoming, Li Dong, Advanced treatment of raw water with high ammonia nitrogen by aeration-BAC filter, J. Chinese Journal of Environmental Engineering. 8(3) (2014) 924-928.

18. Liu Jianguang, Zhang Xiaojiang, Wang Zhansheng, Biological activated carbon filter treatment of high ammonia nitrogen source water, J. China Water \& Wastewater. 19(12) (2003) 61-64.

19. Lv Xiwu, Yan Xushi, BAC removal practices and mechanisms of ammonia, J. Shanghai Environmental Science. 7(1) (1988) 13-16.

20. Yi Yane, Hu Zhonghua, Shen Xinqiang, Removal of Ammonia and Nitrite by Biological Activated Carbon Fiber and Identification of Predominant Degradation Species, J. Research of Environmental Sciences. 6(21) (2008) 197-200.

21. Yang Fan, Li Feiyue, Zhao Ling, Influence of Biochar on the Transformation of Ammonia Nitrogen in Soils, J. Journal of Agro-Environmental Science. 32(5) (2013) 1016-1020.

22. Shi Xiaoxu, Wang,Chong, Gao Mengke, Effect of biochar adsorption of ammonia nitrogen in the slurry, J. Agricultural Science\&Technology and Equipment. (2) (2015)3-5.

23. Shang Guofeng, Zhang Han, Shen Yifei, Removal of Ammonia Nitrogen in Aqueous Samples by Biochar Immobilized Nitrifying Bacteria, J. Journal of Shanghai Jiaotong University (Agricultural Science). 3(2) (2014) 44-47.

24. Gao Fei, Experimental research of biological carbon adsorption of ammonia removal, J. Water Supply and Drainage and Environmental Engineering academic papers. (2014) 12.

25. Zheng Zeng, Preparation of biochar form aquatic eco-remediation plants and their sorption on ammonium and phosphate, D. Zhejiang University master's thesis. (2013).

26. Liu Jianguang, Zhang Xiaojian, Wang Zhansheng, Influence of temperature on treating nitrification of high ammonia nitrogen source water in biological carbon filter, J. China Environmental Science. 24(2) (2004) 233-236.

27. Ma Fengfeng, Zhao Baowei, Lian Bin, Adsorption Characteristics of Ammonium onto Biochar Derived form Corn Straw, J. Journal of LanZhou Jiaotong University. 34(1) (2015) 125-132.

28. Zheng Yangqing, Yu Qiangqiang, Wang Haitao, Preparation of biochars form biogas residue and adsorption of ammonia-nitrogen in biogas slurry, J. CIESC Journal. 65(5) (2014) 1856-1867.

29. Li Feiyue, Xie Yue, Shi Lei, Adsorption of ammonia nitrogen in waste water using rice husk derived biochar, J. Chinese Journal of Environmental Engineering. 9(3) (2015) 1221-1226.

30. Zhang Yang, Li Zifu, Zhang Lin, Adsorption characters of ammonium-nitrogen in aqueous solution by modified corn cob biochars, J. CIESC Journal. 65(3) (2014) 960-966.

31. Xing Ying, Li Xinqing, Zhou Zhihong, Adsorption and Kinetics of Ammonium form Aqueous Medium onto Biochar, J. Earth and Environment. 39(4) (2011) 511-516.

32. Ning Liu, Zhentao Sun, Zhengchao Wu, Adsorption Characteristics of Ammonium Nitrogen by Biochar from Diverse Origins in Water, J. Advanced Materials Research. (2013) 305-312.

33. Simon Kizito, Shubiao Wu, W. Kipkemoi Kirui, Evaluation of slow pyrolyzed wood and rice husks biochar for adsorption of ammonium nitrogen from piggery manure anaerobic digestate slurry, J. Science of the Total Environment. (2015) 102-112.

34. Sun L, Wan S, Luo W, Biochars prepared from anaerobic digestion residue, palm bark, 
and eucalyptus for adsorption of cationic methylene blue dye: characterization, equilibrium, and kinetic studies, J. Bioresource Technology. 140 (2013) 406-413.

35. Ding Dahu, Zhao Yingxin, Yang Shengjiong, Adsorption of cesium from aqueous solution using agricultural residue: equilibrium, kinetic and thermodynamic modeling studies, J. Water Res. (2013) 2563-2571.

36. Liu H, Dong Y, Liu Y, Screening of novel low-cost adsorbents from agricultural residues to remove ammonia nitrogen from aqueous solution, J. J Hazard Mater. (2010) 6-1132.

37. Liu N, Sun Z, Wu Z-C, Adsorption characteristics of ammonium nitrogen by biochar from diverse origins in water, J. Adv Mater Res. 664 (2013) 12-305.

38. Zhu K, Fu H, Zhang J, Studies on removal of $\mathrm{NH}^{4+}-\mathrm{N}$ from aqueous solution by using the activated carbons derived from rice husk, J. Biomass Bioenergy. 43 (2012) 18-25.

39. Huang Haiming, Xiao Xianming, Yan Bo, Ammonium removal from aqueous solutions by using natural Chinese (Chende) zeolite as adsorbent, J. Hazard Mater. (2010) 247-252.

40. Sica M, Duta A, Teodosiu C, Thermodynamic and kinetic study on ammonium removal from a synthetic water solution using ion exchange resin, J. Clean Techno Environ Policy. 16 (2014) 9-351.

41. Han Xue, Study on absorption of ionized nitrogen by carbonized wheat straw, J. Lanzhou: Master Dissertation of Lanzhou University of Technology. 2012(in Chinese).

42. Novak JM, Busscher WJ, Watts DW, Short-term CO2 mineralization after additions of biochar and switch grass to a Typical Kandiudult, J. Geoderma. 154 (2010) 8-281.

43. Thornton A, Pearce P, Parsons SA, Ammonium removal from digested sludge liquors using ion exchange, J. Water Res. 41(2) (2007) 9-433.

44. N. Wang, Y.W. Hou, J.J. Peng, Research progress on sorption of organic contaminants to biochar, J. Environmental Chemistry. (2012) 287-295.

45. Y.P. Wang, Y. Liu, Y.H. Dong, Adsorption of palygorskite on ammonia nitrogen in waste water, J. Journal of Agro-Environment Science. (2008) 1525-1529.

46. X.B. Wang, Y.WANG, S.C.LU, Removal effects of $\mathrm{NH}^{4+}-\mathrm{N}$ and $\mathrm{P}$ from water by modified kaolinite, J. Journal of Agro-Environment Science. (2010) 1784-1788.

47. L. Sun, J.Y Zhang, Research on chemical industry water deep disposal effects with coagulation and activated carbon adsorption, J. Northern Environmental. (91) (2010) 13-15.

48. H.B. Zhen, Y.Y. Hu, J.H. Cheng, Adsorption of $\mathrm{Cu}^{2+}, \mathrm{Ni}^{2+}$ and $\mathrm{Cd}^{2+}$ by chitosan cross-linked zeolite beads, J. Acta Scientiae Circumstantiate. (2011) 19-28.

49. Demirbas A, Effects of temperature and particle size on bio-char yield from pyrolysis of agricultural residues, J. J Anal Apply Pyrolysis. (2004) 8-243.

50. Saltali K, Sari A, Aydin M, Removal of ammonium ion from aqueous solution by natural Turkish (Yildizeli) zeolite for environmental quality, J. J Hazard Mater. 141(1) (2007)63-258.

51. Huang H, Xiao X, Yang L, Ammonium removal from aqueous solutions by using natural Chinese (Chende) zeolite as adsorbent, J. J Hazard Mater. 175(1-3) (2010) 52-247.

52. Wen D, Ho YS, Tang X, Comparative sorption kinetic studies of ammonium onto zeolite, J. J Hazard Mater. 133(1-3) (2006) 6-252.

53. Wang Shaobin, Max Lu G Q, Effects of acidic treatments on the pore and surface properties of Ni catalyst supported on activated carbon, J. Carbon. 36(3) (1998) 283-292.

54. Wahab Mohamed Ali, Boubakri Hatem, Jellali Salah, Characterization of ammonium retention processes onto Cactus leaves fibers using FTIR, EDX and SEM analysis J, J. 
Hazard. Mater. 242 (2012) 101-109.

55. Liu Haiwei, Dong Yuanhua, Wang Haiyun, Ammonium adsorption from aqueous solutions by strawberry leaf powder equilibrium, kinetics and effects of coexisting ions, J. Desalination. 263 (2010) 70-75.

56. Kucic D, Cosic I, VukovicM, Sorption kinetic studies of ammonium from aqueous solution on different inorganic and organic media, J. Acta Chim Slov. 60 (2013) 19-109.

57. Qu B, Zhou J, Xiang X, Adsorption behavior of Azo Dye C.I. Acid Red 14 in aqueous solution on surface soils, J. J Environ Sci. 20 (2008) 9-704.

58. Saltali K, Sari A, Aydin M, Removal of ammonium ion from aqueous solution by natural Turkish (Yildizeli) zeolite for environmental quality, J. J Hazard Mater. 141 (2007) 63-258.

59. Ahamedna M, Marshall WE, Rao RM, Production of granular activated carbons from selected agricultural by-products and evaluation of their physical, chemical and adsorptive properties, J. Bioresour Technol. (2000) 23-113.

60. Al-Wabel MI, Al-Omran A, El-Naggar AH, Pyrolysis temperature induced changes in characteristics and chemical composition of biochar produced from conocarpus wastes, J. Bioresour Technol. 2013(131) 9-374.

61. Keiluweit M, Nico Peter S, ohnson Mark G, Dynamic molecular structure of plant biomass-derived black carbon (biochar), J. Environ Sci Technol. 44 (2010) 53-1247.

62. Abdulrazzaq $\mathrm{H}$, Hamdan $\mathrm{J}$, Ahmed $\mathrm{H}$, Characterization and stabilisation of biochars obtained from empty fruit bunch, wood, and rice husk, J. Bioresources. 9 (2014) 98-2888.

63. Keiluweit M, Nico Peter S, Ohnson Mark G, Dynamic molecular structure of plant biomass-derived black carbon (biochar), J. Environ Sci Technol. 44 (2010) 53-1247.

64. Rajkovich S, A, Hanley K, Hyland C, Corn growth and nitrogen nutrition after additions of biochars with varying properties to a temperate soil, J. Biol Fertil Soils. 48(3) (2011) 271-84.

65. Nidheesh PV, Gandhimathi R, Ramesh ST, Kinetic analysis of crystal violet adsorption on to bottom ash, J. Turk J Eng Environ Sci. 36 (2012) 62-249.

66. Hema M, Arivoli S, Comparative study on the adsorption kinetics and thermodynamics of dyes onto acid activated low cost carbon, J. Int J Phys Sci. 2(1) (2007) 7-10.

67. Long XL, Cheng H, Xin ZL, Adsorption of ammonia on activated carbon from aqueous solutions, J. Environ Prog. 27(2) (2008) 33-225. 